\title{
Clinical response to azacitidine therapy depends on microRNA-29c (miR-29c) expression in older acute myeloid leukemia (AML) patients
}

\author{
Aleksandra Butrym¹,2, Justyna Rybka ${ }^{1}$, Dagmara Baczyńska ${ }^{3}$, Rafał Poręba ${ }^{4}$, \\ Kazimierz Kuliczkowski ${ }^{1}$, Grzegorz Mazur ${ }^{4}$ \\ ${ }^{1}$ Department of Hematology, Blood Neoplasms and Bone Marrow Transplantation, Wroclaw Medical University, Wroclaw, \\ Poland \\ ${ }^{2}$ Department of Physiology, Wroclaw Medical University, Wroclaw, Poland \\ ${ }^{3}$ Department of Forensic Medicine, Molecular Techniques Unit, Wroclaw Medical University, Wroclaw, Poland \\ ${ }^{4}$ Department of Internal, Occupational Diseases, Hypertension and Clinical Oncology, Wroclaw Medical University, Wroclaw, \\ Poland
}

Correspondence to: Aleksandra Butrym, e-mail: aleksandra.butrym@gmail.com

Keywords: miR-29c, acute myeloid leukemia, azacitidine, response to therapy, expression

Received: October 05, 2015

Accepted: January 23, 2016

Published: February 03, 2016

\section{ABSTRACT}

Acute myeloid leukemia (AML) is a heterogeneous disease with different clinical course and prognosis. microRNA-29 (miR-29) family of non-coding small RNAs can play an important role in pathogenesis of $A M L$, but also can influence response to therapy.

The purpose of the study was to evaluate miR-29c expression in AML patients in relationship to clinical parameters and response to chemotherapy, including azacitidine.

Materials and Methods: miR-29c expression has been analyzed using RT-PCR in 95 bone marrow specimens from newly diagnosed AML patients in comparison to 20 healthy subject.

Results: We showed up-regulated miR-29c expression in AML patients which was linked also to higher risk of disease relapse after achieving complete remission. In subset of elderly AML patients treated with azacitidine, low miR-29c expression at diagnosis correlated with good response to therapy.

Conclusions: miR-29c is of prognostic value and influences response to azacitidine treatment in older AML patients.

\section{INTRODUCTION}

Acute myeloid leukemia (AML) is a hematopoietic disorder characterized by increased, uncontrolled proliferation of progenitor cells and their blocked differentiation. In AML there is a bone marrow blast count over $20 \%$ and poor prognosis of patients with this diagnosis. In recent times there has been a huge improvement in the therapy of adult AML, but still it is difficult to find optimal therapeutic option. The population of AML patients is very heterogenous and at the moment of disease diagnosis all patients are stratified to different risk groups with different prognosis. Although there are many prognostic factors, particularly molecular and cytogenetic, we need the new one for better patient allocation and individual treatment. The issue of AML treatment and chemotherapy dosing specially regards older patients, in which we do not have standard treatment, thus overall survival and response rates remain poor. Recently the results of international phase III trial of azacitidine in the therapy of older AML patients has been published, showing azacitidine as a good option for this group of patients [1].

MicroRNAs (miRs) are short non-coding RNAs, 19-25 nucleotides long, which have an important role in regulation of fundamental processes of cell development, differentiation, growth and proliferation. Dysregulation of miRs expression can contribute to pathogenesis and prognosis of many cancers, including AML $[2,3]$. 
MiR-29c belongs to miR-29 family, together with miR-29a and miR-29b. All mature miR-29 have highly homologous sequences, but different isoforms of miR-29 family can have different functions. In AML miR-29 has been shown to act as tumor suppressors and regulators of cell proliferation and apoptosis, thus it has an important role in normal and malignant haematopoiesis [4]. Results of miR-29 expression in AML patients has been so far quite different and linked to heterogeneous subtypes of AML [5], but no reports are known regarding the role of miR-29 in response to new kind on AML treatment with azacitidine.

The purpose of this study was to evaluate miR-29 expression in newly diagnosed AML patients in comparison to healthy controls, relationship with clinical features of the disease and analysis of any potential influence of miR-29 expression on efficacy of azacitidine in subsets of older AML patients.

\section{RESULTS}

We showed higher miR-29c expression in AML patients in comparison to control healthy group $(p<0.0001)$, Figure 1 .

Experiments performed after induction chemotherapy in AML patients showed significant change in miR-29c expression $(p<0.05)$. Achieving complete remission (CR) after initial treatment was linked to drop in miR-29c expression.

Patients who achieved CR with higher than median miR-29c expression at diagnosis and were at higher risk of relapse $(p=0.02)$.

miR-29c expression at diagnosis also determined patients survival $(p=0,03951)$. Lower miR-29 expression was associated with prolonged survival in comparison to higher expression in AML group. Figure 2.

\section{Patients treated with azacitidine}

We observed, that lower miR-29c expression at diagnosis in AML patients treated with azacitidine was correlated with good response to azacitidine and remission achieving $(p=0.03)$. Figure 3 .

The same, time of remission duration was longer in patients who had low miR-29c expression after chemotherapy ( $p<0.05$, coeff .905581) Figure 4.

\section{DISCUSSION}

AML is heterogenous disease with different clinical course and prognosis. In this disease it is very important to determine risk factors for this population of patients,

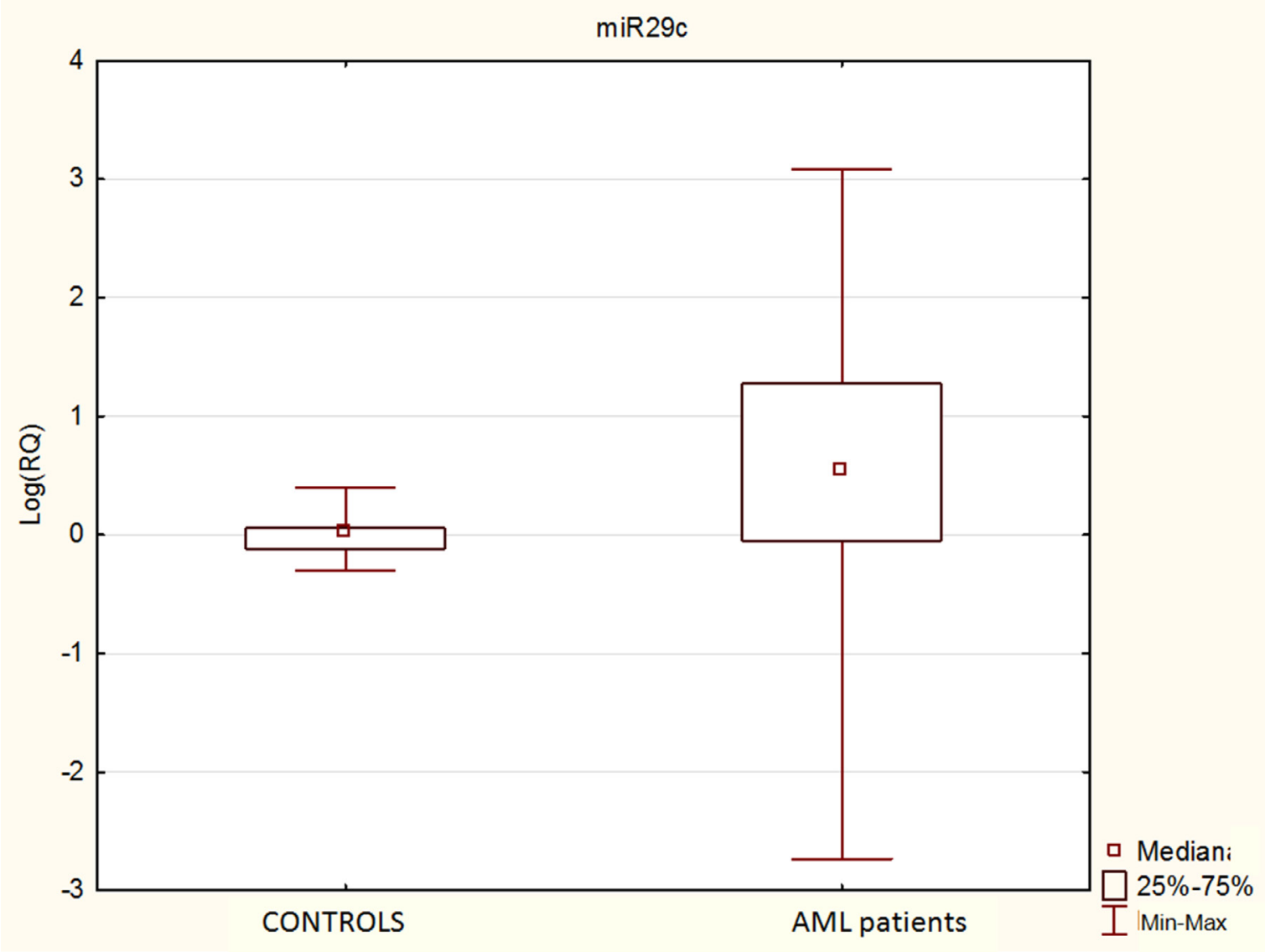

Figure 1: miR-29c expression in AML patients comparing to control group. 
for good stratification and treatment. The group of older patients in AML has particularly poor prognosis and still remains without optimal and effective therapy due to possible toxicity and comorbidities. In the last few years low dose therapy with hypometylating agents, such as azacitidine and decitabine has shown some promising results, prolonging overall survival with better quality of life $[1,6,7]$. As to our knowledge, our study is a first report linking miR-29c expression to the results of azacitidine therapy in AML patients.

It has been already proved, that miR-29 family had been involved in the regulation of many important processes leading to cancer genesis and progression, acting mainly as tumor suppressor [8]. In this study we showed significantly higher miR-29c expression in AML patients comparing to healthy controls and high expression was linked to increased risk of disease relapse. Deregulation of miR-29 family expression can be also involved in AML pathogenesis but it differs depending on scientific reports. Wang et al. reported decreased miR-29a in adult AML patients and underlined its role in monocytic and granulocytic differentiation [9].
Contrary, Han et al. demonstrated high expression levels of miR-29a in similar patient population, with its impact on self-renewal capacity in hematopoietic progenitors [10]. Up-regulated expression of miR-29c in AML with aberrant cytoplasmic NPM1 localization was found by Garzon et al. [11].

As miR-29 targets DNA methyltransferases (DNMTs) and thus has its epigenetic effect on AML cells, we tended to verify relationship between therapy with hypomethylating agent such azacitidine and miR29c expression in subset of older AML patients [7, 12]. Our results indeed confirmed that low expression of miR-29c in elderly AML patients was linked to good response to therapy and prolonged duration of complete remission. Therapy with azacitidine usually requires 3 to 6 cycles to see any effectiveness of the drug and there are patients who will not respond to azacitidine. Determination of miR-29c expression at diagnosis could help to avoid unnecessary costs and ineffective therapy. In 2010 Blum et al. showed that clinical response to another hypomethylating agent decitabine in older AML patients was correlated with miR-29b

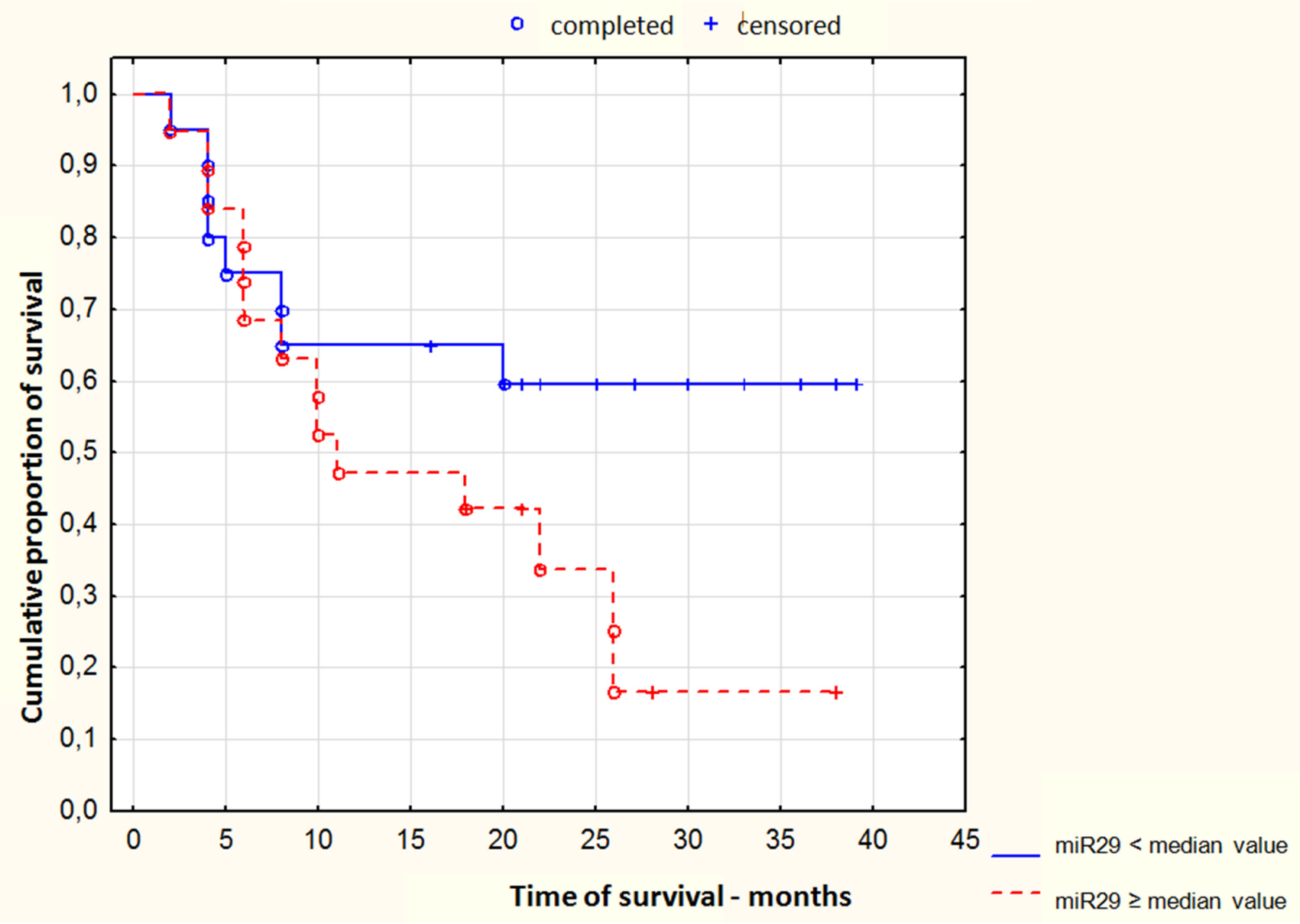

Figure 2: Kaplan-Meier curve of probability of AML patients survival depending on miR-29c expression at the moment at diagnosis. Me - median value of expression. 


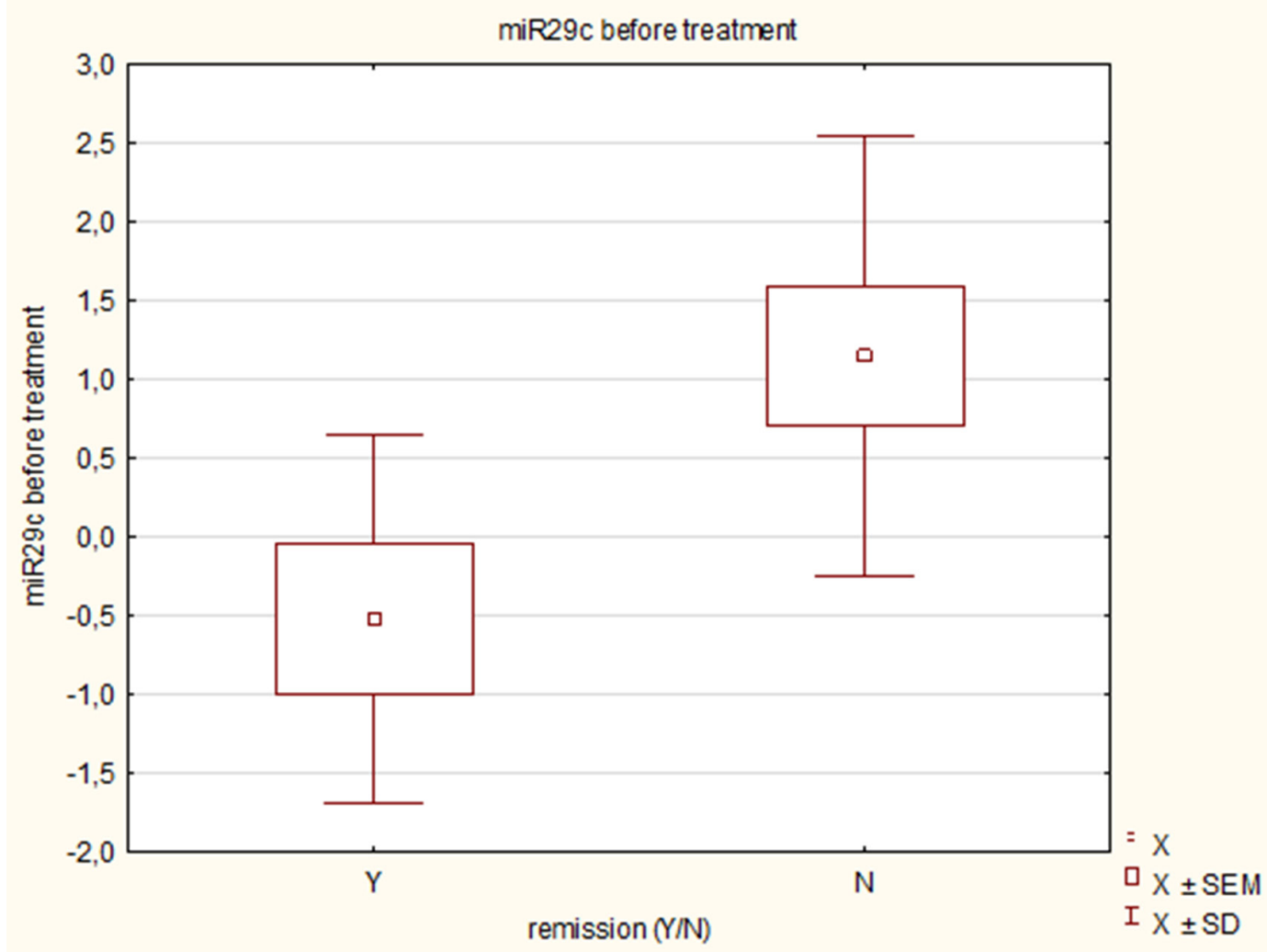

Figure 3: Response to azacitidine treatment depending on miR-29c expression at diagnosis in acute myeloid leukemia patients.

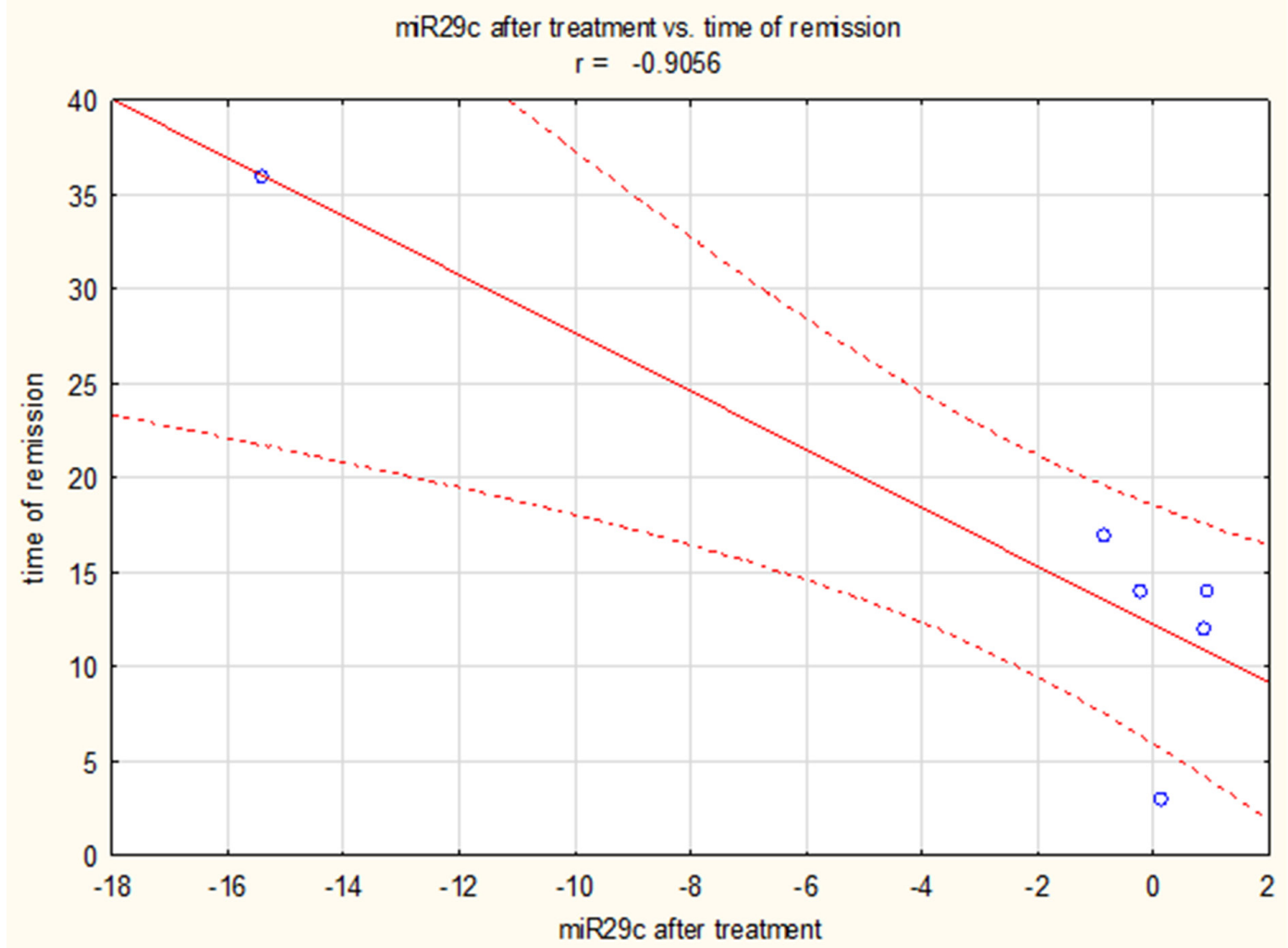

Figure 4: Duration of complete remission in AML patients depending on miR-29c expression after chemotherapy. 
expression [7]. The miR-29 family has complementary structure to 3'-UTR of methyltransferases DNMT3a and DNMT3b [4]. In cases with low miR-29b expression, restoration of miR-29b in AML cells reduced DNA hypermethylation and induced re-expression of previously hypermethylated suppressor genes by direct binding to DNMTs [12]. Blum et al. continued their investigation on miR-29 family and bortezomib and decitabine treatment in AML [113]. They showed possibility of up-regulation of miR-29b expression by bortezomib and increased sensitivity of tumor cells to decitabine.

Concluding, we are the first to show, that miR-29c in older AML patients can determine response to new kind of antileukemic therapy with azacitidine. As this treatment is well tolerated and safe in this patients population, it is important to have a tool for selection of patients who will benefit from therapy. miR-29c can have predictive value for treatment response and survival in acute myeloid leukemia patients, but it should be validated as the stratification tool in bigger AML cohort.

\section{MATERIALS AND METHODS}

\section{Patients characteristics}

The study included 95 patients (aged $60.2 \pm 15.0$, $22-90$, Male $=61 \%$ ) with newly diagnosed AML. Samples of the bone marrow for miR-331 expression analysis were collected before start of chemotherapy and repeated after completed induction chemotherapy (40 patients). Patients were treated in the Department of Hematology, Blood Neoplasms and Bone Marrow Transplantation of Wroclaw Medical University, Wroclaw, Poland. A control group of 20 healthy subjects was also taken into account (aged $64.2 \pm 10.5,39-80$, Male $=65 \%$ ). According to AML FAB classification, 7 patients had AML M0, 34 had M1, 29 had M2, 14 had M4 and 11 had M5. There were 73 patients with primary leukemia and 22 patients with leukemia secondary to myelodysplastic or myeloproliferative syndrome. Summary of patients' characteristics is present in Table 1.

After diagnosis, 56 patients were treated with standard induction intensive chemotherapy (daunorubicin plus cytarabine $3+7$ ), 27 received low dose chemotherapy (low dose cytarabine or azacitidine) and 12 best supportive care only. After completion of induction therapy response to treatment was evaluated. CR was defined by Cheson criteria [14]. Also bone marrow samples were re-evaluated for miR-29 expression in 40 patients. Patients were followed up for median 21 month (range 1-40 months).

\section{AML patients treated with azacitidine}

There were 17 newly diagnosed AML patients, not suitable for intensive chemotherapy, treated with azacitidine (4 women and 13 men, aged 65-90 years, median age 75 years). Azacitidine was administered $75 \mathrm{mg} / \mathrm{m}^{2}$ subcutaneously, on days 1-7 of 28-day cycles. Patients received 1-35 cycles of azacitidine (median 7 cycles). 6 patients achieved complete remission, 6 had partial response or disease stabilization and 5 did not respond to therapy. At the time of analysis, all patients, except one, were dead.

\section{Ethical statement}

Research was carried out in compliance with the Helsinki Declaration. For the study approval of Bioethical Committee of Wroclaw Medical University was obtained. Written informed consent for study was obtained from all the participants.

\section{Isolation and expression analysis of microRNAs}

Bone marrow mononuclear cells (PBMC) were isolated by Ficoll-Hypaque density gradient centrifugation. Total RNA and microRNA were extracted from collected AML mononuclear cells using mirVana $^{\mathrm{TM}}$ miRNA Isolation Kit (Ambion) according to the protocol of the manufacturer. Then $5 \mu \mathrm{l}$ total miRNA was used as a template into synthesis of cDNA using TaqMan MicroRNA Trasncription Reaction Kit (Applied Biosystems) and $3 \mu \mathrm{l}$ specific miRNA primers from the TaqMan MicroRNA Assays (Applied Biosystems). Individual reaction was carried out in 15 $\mu \mathrm{l}$ total volume in thermal condition: $16^{\circ} \mathrm{C}$ for $30 \mathrm{~min}, 42^{\circ}$ for $30 \mathrm{~min}, 85^{\circ} \mathrm{C}$ for $5 \mathrm{~min}$. TaqMan MicroRNA Assays for miR29 (hsa-miR-29), and RNU48 were used. The expression level of each microRNA was measured in relative real-time PCR method using TaqMan Gene Expression Assays and TaqMan Fast Universal PCR Master Mix (Applied Biosytems). All reactions were done in triplicate in a total volume of $20 \mu \mathrm{l}$ on 96-well plates. The real-time PCR was performed on 7900HT Fast Real-Time PCR System (Applied Biosystems) under thermal cycling conditions: $20 \mathrm{~s}$ at $95^{\circ} \mathrm{C}$ and 40 cycles of $1 \mathrm{~s}$ at $95^{\circ} \mathrm{C}$ and $20 \mathrm{~s}$ at $60^{\circ} \mathrm{C}$. For quantification, the samples were normalized against the expression of RNU48 miR. Relative quantification factors (RQ) for the examined miRs were calculated using ${ }^{\Delta \Lambda} \mathrm{CT}$ method.

\section{Statistical analysis}

The differences in means of gene expressions between the study and the control patients were estimated using t-Student's test (for independent samples). To examine the time it takes for death and remission to occur, a Cox's regression was applied [15]. The difference between the gene expressions before and after treatment was estimated using robust regression and multivariate approach [16]. The computation was performed in R software [17] and based on the simulation technique known as Gibbs sampling in WinBUGS platform [18]. Kaplan-Meier survival curves were used to determine any significant relationship between miR-29c expression and clinical outcome. Results were considered statistically significant when $p$ was $<0.05$. 
Table 1: Clinical characteristics of patients with AML

\begin{tabular}{|c|c|}
\hline Characteristics & Cases \\
\hline \multicolumn{2}{|l|}{ Sex } \\
\hline Male & 56 \\
\hline Female & 39 \\
\hline \multicolumn{2}{|l|}{ Age (years) } \\
\hline Range & $22-90$ \\
\hline Median & 61 \\
\hline \multicolumn{2}{|l|}{ FAB subtype } \\
\hline M0 & 7 \\
\hline M1/M2 & 63 \\
\hline M4/M5 & 25 \\
\hline \multicolumn{2}{|l|}{ WBC (G/L) } \\
\hline Range & $0.2-295$ \\
\hline Median & 14 \\
\hline \multicolumn{2}{|l|}{ HGB g\% } \\
\hline Range & $5.8-13.1$ \\
\hline Median & 9.3 \\
\hline \multicolumn{2}{|l|}{$\operatorname{PLT}(\mathrm{G} / \mathrm{L})$} \\
\hline Range & $2-310$ \\
\hline Median & 65 \\
\hline \multicolumn{2}{|l|}{ Lactate dehydrogenase (LDH) U/I } \\
\hline Range & $108-4565$ \\
\hline Median & 340 \\
\hline \multicolumn{2}{|l|}{ Blasts in bone marrow } \\
\hline$<50 \%$ & 35 \\
\hline$\geq 50 \%$ & 60 \\
\hline \multicolumn{2}{|l|}{ Cytogenetics } \\
\hline Farorable & 5 \\
\hline Intermediate & 39 \\
\hline Unfavorable & 51 \\
\hline \multicolumn{2}{|l|}{ Chemotherapy } \\
\hline Intensive & 56 \\
\hline Low dose & 27 \\
\hline Best supportive care & 12 \\
\hline Molecular tests & Total 60 patients \\
\hline AML/ETO (positive/negative) & $4 / 56$ \\
\hline CBFb-MYH11 (positive/negative) & $2 / 58$ \\
\hline NPM1 (positive/negative) & $7 / 53$ \\
\hline FLT3/ITD (positive/negative) & $13 / 47$ \\
\hline \multicolumn{2}{|l|}{ Complete remission } \\
\hline Yes (total) & 51 \\
\hline Yes (after 1st line therapy) & 36 \\
\hline No & 44 \\
\hline
\end{tabular}




\begin{tabular}{|l|c|}
\hline Duration of remission (months) & $2-54$ \\
\hline Range & 20 \\
\hline Median & \\
\hline Time to relapse (months) & $3-23$ \\
\hline Range & 12 \\
\hline Median & \\
\hline Survival (months) & $0-55$ \\
\hline Range & 3 \\
\hline Median & \\
\hline
\end{tabular}

\section{GRANT SUPPORT}

The study has been supported by Wroclaw Medical University Young Scientists Grant Pbmn 140.

\section{CONFLICTS OF INTEREST}

The authors declare they have no conflicts of interest.

\section{REFERENCES}

1. Dombret H, Seymour JF, Butrym A, Wierzbowska A, Selleslag D, Jang JH, Kumar R, Cavenagh J, Schuh AC, Candoni A, Récher C, Sandhu I, Bernal Del Castillo T, et al. International phase 3 study of azacitidine vs conventional care regimens in older patients with newly diagnosed AML with $>30 \%$ blasts. Blood. 2015; 126:291-299.

2. Butrym A, Rybka J, Baczyńska D, Tukiendorf A, Kuliczkowski K, Mazur G. Low expression of microRNA-204 (miR-204) is associated with poor clinical outcome of acute myeloid leukemia (AML) patients. J Exp Clin Cancer Res. 2015; 34:68.

3. Butrym A, Rybka J, Baczyńska D, Tukiendorf A, Kuliczkowski K, Mazur G. Expression of microRNA-331 can be used as a predictor for response to therapy and survival in acute myeloid leukemia patients. Biomark Med. 2015; 9:453-460.

4. The Kollinerova S, Vassanelli S, Modriansky M. role of miR-29 family members in malignant hematopoiesis. Biomed Pap Med Fac Univ Palacky Olomouc Czech Repub. 2014; 158:489-501.

5. Gong JN, Yu J, Lin HS, Zhang XH, Yin XL, Xiao Z, Wang F, Wang XS, Su R, Shen C, Zhao HL, Ma YN, Zhang JW. The role, mechanism and potentially therapeutic application of microRNA-29 family in acute myeloid leukemia. Cell Death Differ. 2014; 21:100-112.

6. Kantarjian HM, Thomas XG, Dmoszynska A, Wierzbowska A, Mazur G, Mayer J, Gau JP, Chou WC, Buckstein R, Cermak J, Kuo CY, Oriol A, Ravandi F, et al. Multicenter,_randomized, open-label, phase III trial of decitabine versus_patient choice, with physician advice, of either supportive_care or low-dose cytarabine for the treatment of older_patients with newly diagnosed acute myeloid leukemia. J Clin Oncol. 2012; 30:2670-2677.

7. Blum W, Garzon R, Klisovic RB, Schwind S, Walker A, Geyer S, Liu S, Havelange V, Becker H, Schaaf L, Mickle J, Devine H, Kefauver C, et al. Clinical response and miR-29b predictive significance in older AML patients treated with a 10-day schedule of decitabine. Proc Natl Acad Sci U S A. 2010; 107:7473-7478.

8. Jiang H, Zhang G, Wu JH, Jiang CP. Diverse roles of miR-29 in cancer (review). Oncol Rep. 2014; 31: 1509-1516.

9. Wang F, Wang XS, Yang GH, Zhai PF, Xiao Z, Xia LY, Chen LR, Wang Y, Wang XZ, Bi LX, Liu N, Yu Y, Gao D, et al. miR-29a and miR-142-3p downregulation and diagnostic implication in human acute myeloid leukemia. Mol Biol Rep. 2012; 39:2713-2722.

10. Han YC, Park CY, Bhagat G, Zhang J, Wang Y, Fan JB, Liu M, Zou Y, Weissman IL, Gu H. microRNA-29a induces aberrant self-renewal capacity in hematopoietic progenitors, biased myeloid development, and acute myeloid leukemia. J Exp Med. 2010; 207:475-489.

11. Garzon R, Garofalo M, Martelli MP, Briesewitz R, Wang L, Fernandez-Cymering C, Volinia S, Liu CG, Schnittger $\mathrm{S}$, Haferlach T, Liso A, Diverio D, Mancini M, et al. Distinctive microRNA signature of acute myeloid leukemia bearing_cytoplasmic mutated nucleophosmin. Proc Natl Acad Sci U S A. 2008; 105:3945-3950.

12. Garzon R, Liu S, Fabbri M, Liu Z, Heaphy CE, Callegari E, Schwind S, Pang J, Yu J, Muthusamy N, Havelange V, Volinia S, Blum W, et al. MicroRNA-29b induces global DNA hypomethylation and tumor suppressor gene reexpression in acute myeloid leukemia by targeting directly DNMT3A and 3B and indirectly DNMT1. Blood. 2009; 113:6411-6418.

13. Blum W, Schwind S, Tarighat SS, Geyer S, Eisfeld AK, Whitman S, Walker A, Klisovic R, Byrd JC, Santhanam_R, Wang H, Curfman JP, Devine SM, et al. Clinical and pharmacodynamic activity of bortezomib and decitabine in acute myeloid leukemia. Blood. 2012; 119:6025-6031.

14. Cheson BD, Bennett JM, Kopecky KJ, Büchner T, Willman CL, Estey EH, Schiffer CA, Doehner H, Tallman MS, 
Lister TA, Lo-Coco F, Willemze R, Biondi A, et al. International Working Group for Diagnosis, Standardization of Response Criteria, Treatment Outcomes, and Reporting Standards for Therapeutic Trials in Acute Myeloid Leukemia. Revised recommendations of the International Working Group for Diagnosis, Standardization of Response Criteria, Treatment Outcomes, and Reporting Standards for Therapeutic Trials in Acute Myeloid Leukemia. J Clin Oncol. 2003; 21:4642-4649.

15. Cox DR. Regression models and life-tables. Journal of the Royal Statistical Society, Series B1972; 34:187-220.

16. Congdon P. Applied Bayesian Modelling. 2003;Wiley, Chichester 118-126.
17. R Core Team. R: A language and environment for statistical computing. Version 3.0.3. 2014 Vienna: R Foundation for Statistical Computing, http://www.r-project.org/]

18. Spiegelhalter D, Thomas A, Best N, Lunn D. WinBUGS. Version 1.4.3. 2003. Cambridge: Imperial College School of Medicine \& Medical Research Council-Biostatistics Unit, www.mrc-bsu.cam.ac.uk/bugs/winbugs/). 